\title{
Notas a respeito do II Colóquio Internacional Hermenêuticas do Feminino: Ecos na/da Casa Comum
}

\author{
Notes on de $2^{\text {nd }}$ International Colloquium \\ Hermeneutics of the Feminine: \\ Echoes in/of the Common Home
}

\author{
Renato Kirchner \\ Ceci Maria Costa Baptista Mariani \\ Luís Gabriel Provinciatto
}

\section{Resumo}

Esta nota versa sobre os trabalhos realizados ao longo do II Colóquio Internacional Hermenêuticas do Feminino: Ecos na/da Casa Comum, realizado entre 18 e 20 de outubro de 2021, em formato on-line, organizado pelo Grupo de Trabalho Ecofeminismo e Ecocultura e sediado pelo Programa de Pós-Graduação em Ciências da Religião da PUC-Campinas. Ela está dividida em três partes, seguindo as atividades do evento: 1) conferências; 2) mesas temáticas; 3) sessões temáticas. Seu objetivo é, em primeiro lugar, dar a conhecer à comunidade científica, sobretudo, à pertencente à área de Ciências da Religião e Teologia os trabalhos aí desenvolvidos com vistas a contribuir para a tecitura de um estado da arte atualizado a respeito do tema proposto pelo colóquio; buscar-se-á realizar isso a partir de uma síntese dos trabalhos; e, em segundo lugar, pretendese ratificar a atualidade da discussão teológica e científico-religiosa em torno às mulheres, ao feminino, ao ecofeminismo e à ecocultura. Finalizase a nota apresentando alguns resultados das investigações feitas pelo 
supracitado Grupo de Trabalho, bem como indicam-se resultados aventados ao término do colóquio.

Palavras-chave: Colóquio. Ecofeminismo. Ecocultura. Casa Comum.

\begin{abstract}
This note addresses the works carried out during the II International Colloquium Hermeneutics of the Feminine: Echoes in/of the Common Home, held between 18 and 20 October 2021, in online format, organized by the Working Group Ecofeminism and Ecoculture and hosted by the Postgraduate Program in Religious Studies of PUC-Campinas. It is divided in three parts, following the activities of the event: 1) conferences; 2) thematic dialogue tables; 3 ) thematic sessions. Its objective is, in the first place, to make known to the scientific community, above all, to those belonging to the area of Religious Studies and Theology, the works developed there with the aim of contributing to the weaving of an updated state of the art regarding the theme proposed by the colloquium; this will be done through a synthesis of the works; and, in the second place, to ratify the actuality of the theological and scientificreligious discussion around women, feminism, ecofeminism and ecoculture. The note ends by presenting some results of the investigations made by the above-mentioned Working Group.
\end{abstract}

Keywords: Colloquium. Ecofeminism. Ecoculture. Common Home.

\title{
Introdução
}

O II Colóquio Internacional Hermenêuticas do Feminino: Ecos na/da Casa Comum foi, indubitavelmente, um evento plural, formado por vozes, rostos e perspectivas teórico-críticas distintas e, ao mesmo tempo, complementares. Antes de descrevê-lo, no entanto, é preciso situá-lo: tratou-se de um evento organizado e realizado pelo Grupo de Trabalho Ecofeminismo e Ecocultura, ${ }^{1}$

\footnotetext{
${ }^{1}$ O GT Ecofeminismo e Ecocultura compõe o projeto Casa Comum e novos modos de habitar interculturalmente: teologia pública e ecologia da cultura em tempos de Covid-19, coordenado pelo Prof. Dr. Alex Villas Boas e sediado no Centro de Investigação em Teologia e Estudos de Religião (CITER), da Universidade Católica Portuguesa (UCP).
} 
liderado pela Profa. Dra. Maria Clara Lucchetti Bingemer, em parceria com os Programas de Pós-graduação em Ciências da Religião, da PUC-Campinas, em Teologia, da PUC-Rio, e em Direitos Humanos e Políticas Públicas, da PUC-PR, juntamente com o Centro de Investigação em Teologia e Estudos de Religião (CITER), da Universidade Católica Portuguesa, com a Faculdade de Teologia da PUC-PR e com o apoio institucional do Programa de Pósgraduação em Ciência da Religião da Universidade Federal de Juiz de Fora e do Praxis - Centro de Filosofia, Política e Cultura, polo Universidade de Évora.

Também deve se dizer que se tratou de um evento que deu maior visibilidade à parceria lusófona Portugal-Brasil criada em torno às discussões teológicas, filosóficas e científico-religiosas a respeito das mulheres, do ecofeminismo e da ecocultura. Uma parceria possível de ser vista já na realização do I Colóquio Internacional Hermenêuticas do Feminino, na Universidade Católica Portuguesa, em Lisboa, nos dias 28 e 29 de janeiro de 2020, cujos resultados se encontram no dossiê "Hermenêuticas do feminino", publicado em 2021 como número especial na Revista Pistis \& Praxis: teologia e pastoral. Contudo, a segunda edição do evento não só estreitou os laços Portugal-Brasil como também "expandiu as fronteiras", contando com a participação de pessoas de outros quatro países: Chile, Espanha, México e Moçambique.

Para esta segunda edição, o colóquio trouxe como motivação temática a Casa Comum, categoria amplamente utilizada pela Encíclica Laudato Si' $(L S)$, do Papa Francisco, publicada em 2015, e pela Agenda 2030 da Organização das Nações Unidas, com o objetivo de ouvir o grito dado pela Terra de que ela padece e está doente. Não só ouvi-la, mas também pensar as causas e os desdobramentos de tal grito, pondo-se a ouvir os ecos da Casa Comum que não ressoam senão na própria Casa Comum. Dentre tais ecos, está o silenciamento da voz das mulheres frente àquela racionalidade que tomou $\mathrm{o}$ neutro, o objetivo, o abstrato e o universal como norma do saber e do ser; ${ }^{3}$ racionalidade que reduziu o particular, o contextual e o diferente a perspectivas marginais, sequer considerando-as como alternativas. $\mathrm{O}$ objetivo, no entanto, não se reduziu a somente dar visibilidade a quem está, ou melhor, a quem foi posta nas fronteiras invisíveis das esferas político-social, econômica e

\footnotetext{
${ }^{2} \mathrm{O}$ dossiê pode ser acessado no seguinte endereço eletrônico: https://periodicos.pucpr.br/index. php/pistispraxis/issue/view/2045.

${ }^{3}$ HENRIQUES, F., Filosofia e gênero.
} 
religiosa, mas pensar o silenciamento de suas vozes como um dos ecos $d a$ e na Casa Comum, assumindo, então, uma posição/postura de vanguarda, "rompendo o silêncio", conforme propõe Ivone Gebara ${ }^{4}$, para que essas vozes sejam ouvidas, acolhidas, compreendidas e integradas. Essa temática foi debatida em três conferências e em duas mesas temáticas, reportadas a seguir.

\section{As propostas das conferências: a interseccionalidade, a aliança e a alquimia}

A conferência de abertura, proferida por Teresa Martinho Toldy, da Universidade Fernando Pessoa (Porto, Portugal), doutora em Teologia pela Escola Superior de Filosofia e Teologia Sankt Georgen (Frankfurt am Main, Alemanha), teve como título Contributos para abordagens interseccionais e partiu do princípio de impossibilidade de haver um conhecimento que seja onipresente, onisciente e onipotente, destacando, na verdade, o caráter situado e contextualizado de toda reflexão teológica e filosófica. Ainda inicialmente, a conferencista apontou a necessidade de se atentar à perspectiva teológicofeminista de sua abordagem, no interior da qual o "feminino", como conceito essencialista, se distingue do "feminismo", como os discursos e as práticas realizadas a partir das mulheres como seres históricos, um conceito no qual o biológico se distingue das construções culturais do que é a mulher. Também trouxe à tona o tema da representação antropológica das mulheres nos documentos eclesiásticos, algo que tem sido retomado por vozes masculinas, que tentam dar legitimidade a discussões que há muito estão consolidadas na teologia feminista, como é o caso, por exemplo, da figura de Deus como "pai" e "mãe". Nesse sentido, um dos propósitos da conferência foi justamente evidenciar as discussões de primeira ordem na teologia feminista e não simplesmente retomar o que há décadas está consolidado, destacando-se a atualidade da discussão a respeito da solidariedade e da fraternidade entre os povos, algo presente também nas Encíclicas Laudato Si' e Fratelli Tutti (2020), bem como aquela sobre os bens necessários para bem viver, dando o exemplo da escassez de água e de como em algumas culturas patriarcais é função das mulheres providenciar tal bem, o que acaba por lhes explorar e expô-las a condições inomináveis em certos casos, conforme demonstra Sarah Clark Miller. ${ }^{5}$

\footnotetext{
${ }^{4}$ GEBARA, I., Rompendo o silêncio.

${ }^{5}$ MILLER, S. C., Resisting Sexual Violence: What Empathy Offers, p. 63-77.
} 
O que a teologia tem a dizer diante desses e de tantos outros cenários? Como ela se posiciona diante de tais situações? Tais perguntas, de acordo com Teresa Toldy, não podem ser simplesmente postas à teologia pastoral, mas, sobretudo, à teologia fundamental, que é quem deve discutir o lugar dos pobres, dos vulnerabilizados, dos sem voz, dos "descartáveis". ${ }^{6}$ Justamente nesse ponto entre em voga a sua proposta de a "hermenêutica interseccional" contribuir para a edificação da teologia, pois essa abordagem hermenêutica pensa social, política, econômica e teologicamente a complexidade dos problemas, percebendo as várias formas de interação entre diferentes concepções, por exemplo, entre as de "raça" e "gênero", como proposto por Kimberle Crenshaw. ${ }^{7}$ A interseccionalidade, então, inibe a abordagem unilateral, negando-se a assumir uma linguagem imparcial, neutra, ou seja, a hermenêutica interseccional toma posição e visa abertamente uma transformação social significativa, logo, ela está de olhos abertos para o mundo. A sua contribuição para a edificação de uma teologia intersecional aborda seis aspectos, destacados por Toldy a partir de Collins e Bilge: ${ }^{8}$ a desigualdade social, o poder, a relacionalidade, o contexto social, a complexidade da análise interseccional crítica e a justiça social. Tal empreitada não pode olhar para um único aspecto, pois todos estão conjugados. A complexidade da própria realidade, portanto, faz da interseccionalidade um conceito complexo. A proposição de uma teologia interseccional, por fim, diferentemente de um saber onipresente, onisciente e onipotente, é contextual, contingente, autorreflexiva e procura sempre a justiça social para todos, logo, trata-se de uma teologia que desmantela os sistemas opressivos, a cultura patriarcal do saber e do ser.

A segunda conferência do colóquio foi proferida por Maria Clara Lucchetti Bingemer, da PUC-Rio, doutora em Teologia Sistemática pela Pontifícia Universidade Gregoriana (Roma, Itália), e teve como título Mulher e Natureza: aliança e analogia (reflexão dialogante com a Laudato Si'). Seu ponto de partida retomou uma das hipóteses levantadas pelo ecofeminismo que contribui para o pensamento teológico, a saber, o domínio da mulher e o da natureza ser algo específico das culturas patriarcais, embora sejam dominações historicamente distintas, não só porque a primeira é muito anterior à segunda, mas porque o domínio da mulher está à base do patriarcalismo, ao passo que o domínio da natureza é um resultado do pensamento moderno

\footnotetext{
${ }^{6} \mathrm{LS} 158$.

${ }^{7}$ CRENSHAW, K., Mapping the Margins, p. 1241-1299.

${ }^{8}$ COLLINS, P, H.; BILGE, S., Interseccionalidade.
} 
e de sua concepção de ciência, já desenvolvida sob a base de uma cultura patriarcal amplamente consolidada. No entanto, isso não significa que com a superação do domínio da natureza, como propõe o pensamento ecológico contemporâneo, a opressão da mulher também seja superada. De acordo com a conferencista, a libertação da mulher é uma luta à parte, mesmo sendo análoga àquela pela libertação da natureza. De fato, a analogia entre o corpo da mulher e natureza é cara ao pensamento (eco)teológico.

Para demonstrá-la, Maria Clara Bingemer propôs o que chamou de uma "reflexão dialogante com a Laudato $S i$ ", partindo não da Encíclica, mas de dois filmes: Nostalgia da luz (2010) e O botão de pérola (2015), ambos dirigidos por Patrício Guzmán. Em síntese, os dois mostram a aterrorizante beleza da natureza. O primeiro, uma verdadeira síntese de memória, história e identidade, situado no deserto de Atacama, mostra a beleza da natureza - em relação à qual o ser humano deve se aproximar em atitude de admiração e encanto $^{9}$ - e os segredos que ela esconde, como, por exemplo, os corpos de milhares de vítimas de uma das mais opressivas ditaturas militares da América Latina, a de Augusto Pinochet, entre 1973 e 1989, no Chile, há muito tempo procurados por suas mães, esposas, irmãs e filhas, que formam o coletivo Mulheres de Calama. O segundo, também situado no Chile, não mais explora a imagem do deserto, mas a da água, fonte de vida e local da existência dos povos originários, por um lado, e cárcere de corpos torturados e mortos pela ditadura chilena, por outro; um cárcere não consentido, no entanto, pois, aos poucos, também a água revela os segredos nela guardados, como é o caso, por exemplo, de Marta Ugarte, encontrada com o rosto intacto às margens da praia de La Ballena, em setembro de 1976. O que ambos demonstram é aquela convivência, comensalidade e comunhão entre ser humano e a natureza de que fala a Laudato Si': uma autêntica cumplicidade, seja a do deserto, seja o da água, reforçada pela fidelidade dos coletivos femininos à vida de seus entes queridos. Cumplicidade e fidelidade que dão pistas para uma hermenêutica teológica do feminino, comprometida não com o ídolo da morte, mas com o Deus da vida.

A partir disso, a conferencista propôs retornar à analogia entre a terra, como o corpo da criação, e o corpo feminino em seus ciclos, sua fertilidade, sua receptibilidade ao outro e em sua esterilidade, quando maltratada, sugada e explorada. A primordialidade dessa analogia remete à figura de Eva, mãe dos

${ }^{9} \operatorname{LS} 11$. 
viventes e cujo nome não é um substantivo, mas um verbo: viver. Contudo, como vivem essas mulheres que, filhas de Eva, são mães de todos os viventes? A pergunta, indubitavelmente, expõe a situação hodierna delas como vítimas de um machismo destruidor, mas também as mostra como resistentes, como mulheres que procuram o caminho da vida, desobedecendo ao poder opressor que lhes dita regras de comportamento e submissão. E como se encontra a natureza? Não muito diferente: vítima de uma exploração, começa a dar sinais nítidos de um desgaste irreparável, resistindo e insurgindo-se, no entanto. Assim como a natureza se defende de um antropocentrismo irresponsável, as mulheres descobrem um caminho contra a agressão a seus corpos, fazendose ouvir coletivamente e causando um impacto possível de ser ouvido social, política e publicamente.

O encerramento do colóquio ficou a encargo de Marilú Rojas Salazar, da Universidade Iberoamericana (Cidade do México, México), doutora em Teologia Sistemática pela Universidade Católica de Louvain (Bélgica), que expos a conferência intitulada De alquimias y otras hibrideces feministas en tiempos de fundamentalismos neocoloniales. Em um primeiro momento, sua conferência se concentrou em torno do conceito "alquimia feminista", definido como uma mescla de corporalidades, sexualidades, diversidades, territórios e realidades que se entrecruzam. A "alquimia feminista", no entanto, não tem a pretensão de concentrar o poder, tampouco de "converter tudo o que toca em ouro". Trata-se, na verdade, da "arte de combinar a vida, os saberes, os desejos, as lutas e a vida cotidiana", como afirmou a conferencista; uma arte que visa transformar tais vidas em melhores espaços de vivência, com melhores e mais saudáveis condições de vida. Nesse sentido, um dos temas abordados por essa alquimia é o da saúde física, mental e espiritual das mulheres, uma luta comum pautada em uma espiritualidade engajada que possui, por um lado, uma dimensão teológica - pneumatológica, de acordo com a conferencista e, por outro, político-profética, que não se submete ao sistema, como também por ela pontuado. Por isso, é preciso pensar uma "alquimia espiritual", prenhe de espiritualidade(s) política(s) e religiosa(s), inclusiva(s) e não exclusiva(s), por exemplo, no tocante às questões de gênero, que não podem ser limitadas aos debates feitos por mulheres feministas.

$\mathrm{O}$ segundo momento da conferência focou justamente nessa alquimia espiritual, que é tanto feminista quanto política, apontando para uma necessária subversão do sistema patriarcalista, algo possível de ser efetuado se, de fato, essa for uma luta coletiva, na qual se mesclam saberes e se parta dos espaços 
micropolíticos em direção aos macros. No entanto, o sistema patriarcalista resiste a seu desmonte e tenta invalidar, desacreditar, desprestigiar e desprezar as causas feministas impondo-lhes rótulos, por exemplo, o da "ideologia de gênero" e o do "exclusivismo". A alquimia feminista, como dito antes, não visa concentrar o poder, pois é uma metodologia "desde baixo", como pontua Marilú, pois se trata de uma luta gestada nas lutas comuns pela defesa da terra, das economias solidárias, pelo resgate e preservação da sabedoria dos povos originários. Por isso, ela não é análoga ao sistema patriarcalista, aliado ao capitalismo neoliberal. Ela não busca o domínio e a exploração, mas surge como resposta às políticas-econômicas devastadoras. Ela não deixa de ser e de fazer política, como destacado por Marcela Lagarde y de los Ríos. ${ }^{10}$ Ela trava uma luta profética e revolucionária contra o sistema que negou às mulheres, às/aos marginalizados, à comunidade LGBTQIA+, aos negros/as o direito à felicidade, afirmando que o que lhes é prazeroso é pecado, culpa ou transgressão. No fundo, trata-se de uma luta pela felicidade de bem viver, sem as penúrias da fome, da insegurança social, das mais variadas violências, etc.

Diante disso, a proposta de Marilú Salazar é a de uma teologia feminista híbrida, conjugando o feminismo social e o feminismo profético que levará a (re)pensar a estrutura eclesial e a própria religião professada e praticada, pois também essa é excludente e patriarcal. Não se trata, porém, de abandonar a religião, mas de, em seu interior, exercer o profetismo, pois as vozes alquímicas são capazes de subverter a ordem estabelecida para sair como a personificação da mulher em Provérbios 1,20-21: "a sabedoria apregoa fora, nas praças levanta a voz: nos lugares ruidosos, ela chama, nos vãos das portas, na cidade, ela pronuncia seu discurso". Percebe-se, por fim, que uma teologia feminista é essencialmente pública, carregada de paixão pela justiça, como finaliza a conferencista.

\section{A continuidade dos diálogos: as mesas e as sessões temáticas}

As discussões iniciadas nas conferências puderam ser continuadas em duas mesas temáticas: a primeira sobre Teologia feminista crítica, composta pela Profa. Dra. Fernanda Henriques, da Universidade de Évora, e pela Profa. Dra. Jaci de Fátima Souza Candiotto, da PUC-PR, e a segunda sobre Ecocultura e a questão da terra, composta pela Profa. Dra. Maria Luísa

\footnotetext{
${ }^{10}$ Apud SALAZAR, M. R, Construyendo el poder desde el feminismo comunitario e desde la teología política feminista, p. 53-64.
} 
Ribeiro Ferreira, da Universidade de Lisboa, e pela Profa. Dra. Maria Cecília Pilla, da PUC-PR.

O objetivo da primeira mesa temática, mediada pelo Prof. Dr. Breno Martins Campos (PUC-Campinas), foi dar visibilidade a temas específicos da teologia feminista em perspectiva crítica, não somente pontuando e localizando a teologia feminista como parte de uma "revolução cultural", ${ }^{11}$ mas abrindo caminhos de interpretação no interior do próprio desenvolvimento teológico; caminhos que "rompem o silêncio" de uma teologia patriarcal e se posiciona na vanguarda dessa que não é somente uma corrente teológico-epistemológica, mas outro modo de fazer teologia. Nesse cenário, o trabalho apresentado por Fernanda Henriques, intitulado Algumas reflexões em torno da tarefa crítica das teologias feministas, teve como principal objetivo oferecer um contributo para desconstruir a assimetria antropológica entre homens e mulheres que o catolicismo tem transmitido ao longo do tempo, denunciando que ele, em geral, exerce um papel fulcral na descriminação que as sociedades ocidentais fazem em relação às mulheres. Para tanto, a oradora destacou que toda teologia feminista deve ser crítica, pois sua razão de ser radica na prática de uma hermenêutica da suspeita em relação à totalidade da tradição teológica, que acabou relegando as mulheres à condição de "segundo sexo". ${ }^{12} \mathrm{O}$ caminho da teologia feminista, então, pressupõe luta e reivindicação, bem como uma mudança de paradigma epistemológico, não mais pautado no imperialismo e na exclusividade, mas na inclusão e no caráter situacional de toda reflexão teológica, estabelecendo, então, um evidente diálogo com a conferência de Teresa Toldy.

Já a comunicação de Jaci Candiotto, intitulada Teologia da Mulher: considerações críticas, dando continuidade à perspectiva de que toda teologia feminista é crítica e necessita de uma hermenêutica da suspeita, desenvolveu seu trabalho em torno de quatro pontos: 1) o que possibilitou a construção de um pensamento teológico feminista crítico; 2) as mulheres como objeto de estudo da teologia; 3) a mulher na teologia como sujeito da reflexão; 4) a teologia feminista e sua contribuição para os direitos humanos das mulheres. Nesse sentido, a oradora revisitou os pontos fundantes e fundamentais da teologia feminista, não só traçando um mapa histórico, mas, sobretudo, indicando que o que antes estava à margem agora já ganhou algum espaço

\footnotetext{
${ }^{11}$ GEBARA, I., Teologia, feminismo e filosofia.

${ }^{12}$ BEAUVOIR, S., O segundo sexo; DALY, M., The Church and the Second Sex.
} 
nas discussões públicas e epistemológicas, muito em razão dos avanços proporcionados pelo Concílio Vaticano II e pelo desenvolvimento da Teologia da Libertação na América Latina. Jaci Candiotto também ressaltou o papel das mulheres por quase dois milênios no cristianismo: a de consumidoras passivas de uma interpretação teológica e de uma proclamação da fé elaboradas exclusivamente por homens, em sua maioria clérigos, de modo que o genitivo "teologia $d a$ mulher" apenas recentemente passou a designar a teologia feita por mulheres e que reflete a respeito do feminino, significando antes a tentativa de explicar teologicamente questões fundamentais à humanidade, por exemplo, a origem do mal, da dor e da morte, associadas ao pecado original, mais especificamente, a Eva. Por fim, a oradora, ao trazer alguns dados para exemplificar a violência, descriminação e injustiça de gênero, colocou as perguntas: qual a influência do pensamento religioso na construção dessa mentalidade de exclusão das mulheres? Quais as possiblidades que a tradição cristã oferece para a emancipação das mulheres? Concluiu afirmando que a teologia feminista, ao buscar criar um novo paradigma de reflexão, colabora na mudança da condição das mulheres nas igrejas e na sociedade, afirmando definitivamente sua dignidade e direito de viver.

A segunda mesa temática, mediada pelo Prof. Dr. Paulo Augusto de Souza Nogueira (PUC-Campinas), trouxe, através da comunicação de Maria Luísa Ribeiro Ferreira, intitulada Algumas orientações ecofeministas, uma perspectiva geral a respeito do ecofeminismo e da ecocultura e, por meio da de Maria Cecília Pilla, intitulada A construção do espaço histórico das mulheres, explorou especificamente um tema presente no interior dos ecofeminismos: a história das mulheres e a relação delas com o trabalho. A primeira exposição trouxe para a discussão três autoras fundamentais para se compreender o surgimento e o desenvolvimento do conceito de ecofeminismo, bem como três suas principais vertentes: a cultural de Vandana Shiva, presente, sobretudo, em sua obra Ecofeminism; ${ }^{13}$ a espiritual e teológica de Sallie McFague, explicitada em The Body of God. An Ecological Theology; ${ }^{14}$ e a vertente sociopolítica de Alicia Puleo, cujas linhas gerais podem ser encontradas em Ecofeminismo: para otro mundo posible..$^{15}$ Além disso, esta primeira comunicação também destacou três pontos de convergência entre as discussões ecofeministas e as ecoculturais: em primeiro lugar, há uma identificação entre a opressão sofrida

\footnotetext{
${ }^{13}$ MIES, M.; SHIVA, V., Ecofeminism.

${ }^{14}$ McFAGUE, S., The Body of God.

${ }^{15}$ PULEO, A. H., Ecofeminismo.
} 
pelas mulheres e pela natureza; em segundo lugar, tanto a teoria quanto a prática feminista conduzem à perspectiva ecológica; em terceiro lugar, na perspectiva ecológica, as mulheres cumprem um papel especial no que diz respeito ao tratamento da natureza. Por fim, essa convergência de princípios faz os ecofeminismos e a ecocultura proporem uma cidadania ambiental, ecológica, pautada na "regra dos 3R" - reduzir, reutilizar e reciclar.

Já a comunicação de Maria Cecilia Pilla explorou uma das possibilidades aventadas pelo ecofeminismo: a de encontrar o papel histórico das mulheres, a quem foi permanentemente negado um lugar, levantando também a questão de se o "feminino" se relaciona tão somente com o "ser mulher", algo trabalhado por Nel Noddings. ${ }^{16}$ Mostra-se, com isso, a necessidade da abordagem histórico-crítica para a construção de uma hermenêutica do feminino, pois, por meio do método histórico-crítico, pode-se construir o papel histórico das mulheres, não mais utilizando o filtro masculino. A construção da história das mulheres, então, coincide com o resgate do papel das mulheres na história. E uma das maneiras de isso ser realizado é justamente através da (re)apropriação do lugar que foi negado às mulheres, o que pode ser feito, por exemplo, por meio do reconhecimento das atividades desqualificadas historicamente pelo fato de serem "próprias à natureza feminina", tal como o cuidado da casa, a preparação dos alimentos e a educação dos/as filhos/as, atividades domésticas que, do ponto de vista patriarcal, não preparam as mulheres para a vida pública e tudo o que nela está envolvido. O espaço público, então, é construído como o espaço da dominação masculina, por excelência, ao passo que o ambiente doméstico com suas atividades é aquele próprio às mulheres, encontrando-se historicamente privadas da vida pública. Logo, para que elas possam assumir o papel de responsáveis em "salvar o planeta", é preciso romper essa barreira e ocupar o espaço público - da vida, da política e dos espaços de decisão.

Além das sessões plenárias, o colóquio também teve chamada aberta para o envio de comunicações científicas, que poderiam ser destinadas a uma das seguintes sessões temáticas: Literatura e questões de gênero, Mística e espiritualidade, Epistemologias da Casa Comum, Teologia feminista, além da sessão destinada à Iniciação científica. Ao todo, foram aprovados 28 trabalhos, cujos resumos podem ser lidos no Caderno de resumos do evento ${ }^{17}$ e cujos textos completos poderão ser acessados quando for publicado o

\footnotetext{
${ }^{16}$ NODDINGS, N., O cuidado.

${ }^{17} \mathrm{O}$ Caderno de resumos pode ser acessado no seguinte endereço eletrônico: https://anaisppgcrpuccampi.wixsite.com/meusite/caderno-de-resumos
} 
quarto volume dos Anais do Programa de Pós-graduação em Ciências da Religião da PUC-Campinas, ${ }^{18}$ que receberão os trabalhos apresentados em tais sessões. As sessões temáticas, além de serem um espaço propício para acolher resultados parciais ou integrais de pesquisas em andamento ou já concluídas, buscaram estabelecer um diálogo com outros grupos de trabalho do projeto Casa Comum e novos modos de habitar interculturalmente que trabalham temas comuns, tangentes ou próximos aos do Grupo de Trabalho Ecofeminismo e Ecocultura.

\section{Conclusão}

O término do II Colóquio Internacional Hermenêuticas do Feminino não coincide com sua conclusão, no entanto. Não só porque as discussões de um colóquio jamais podem dar-se por encerradas, concluídas, perfeitamente acabadas, pois a função desse tipo de evento é dar a pensar, instigar o debate, expor perspectivas - confluentes ou não. Isso, sem dúvida, foi realizado, em maior ou menor medida, nas conferências, nos diálogos estabelecidos das mesas temáticas e, sobremaneira, nos trabalhos apresentados nas sessões temáticas, provenientes de estudantes de várias instituições do Brasil e do exterior. $\mathrm{Na}$ verdade, poder-se-á dizer que as atividades aí iniciadas se concluirão quando vir à tona o novo dossiê que está sendo organizado pelo Grupo de Trabalho Ecofeminismo e Ecocultura e que será publicado na Ephata-Revista Portuguesa de Teologia, editada pela Faculdade de Teologia da Universidade Católica Portuguesa, no segundo semestre de 2022. Tratase, de igual modo que o dossiê publicado na Revista Pistis \& Praxis, de um resultado do Colóquio, que reunirá não só os trabalhos aí desenvolvidos, mas também as pesquisas em andamento no supracitado grupo de trabalho.

Por ora, o que a presente nota destaca é o que se pode chamar de a construção de um estado da arte das hermenêuticas do feminino, que, longe de privilegiar essa ou aquela abordagem, se constrói multidisciplinarmente, o que, por consequência, implica em um conjunto de métodos. Tal estado da arte, porém, também está longe de ser finalizado, afirmando-se que essa é uma das principais - e mais difíceis - tarefas que um Grupo de Trabalho deve cumprir para a consolidação de um tema de investigação. Indubitavelmente,

\footnotetext{
${ }^{18}$ Os anais do II Colóquio Internacional Hermenêuticas do Feminino, quando publicados, poderão ser acessados através do seguinte endereço eletrônico: https://anaisppgcrpuccampi. wixsite.com/meusite/edicoes.
} 
a realização da segunda edição de um colóquio é a demonstração de que isso está a ser feito e a comprovação de que há muito ainda o que se realizar.

\section{Referências bibliográficas}

BEAUVOIR, S. O segundo sexo. Rio de Janeiro: Nova Fronteira, 2008 BÍBLIA de Jerusalém. São Paulo: Paulus, 2002.

COLlinS, P, H.; BILGE, S. Interseccionalidade. São Paulo: Boitempo, 2020 .

CRENSHAW, K. Mapping the Margins: Intersectionality, Identity Politics, and Violence Against Women of Color. Stanford Law Review, v. 43, n. 6, 1991. p. 1241-1299.

DALY, M. The Church and the Second Sex. New York: Harper \& Row, 1968.

GEBARA, I. Rompendo o silêncio: uma fenomenologia feminista do mal. Petrópolis: Vozes, 2000.

GEBARA, I. Teologia, feminismo e filosofia. Revista Cult, v. 31, n. 133, 2009. Disponível em: <https://revistacult.uol.com.br/home/teologia-feminismo-efilosofia/>. Acesso em: 28 out. 2021.

HENRIQUES, F. Filosofia e gênero: outras narrativas sobre a tradição ocidental. Lisboa: Colibri, 2016.

McFAGUE, S. The Body of God. An Ecological Theology. Minneapolis: Fortress Press, 1993.

MIES, M.; SHIVA, V. Ecofeminism. New Jersey: Zed Books, 1993.

MILLER, S. C. Resisting Sexual Violence: What Empathy Offers. In: TEAYS, W. (Ed.). Analyzing Violence Against Women. New York: Springer, 2019. p. 63-77.

NODDINGS, N. O cuidado: uma abordagem feminino à ética e à educação moral. São Leopoldo: Editora Unisinos, 2003.

FRANCISCO PP. Carta Encíclica Fratelli Tutti. São Paulo: Paulus, 2020.

FRANCISCO PP. Carta Encíclica Laudato Si’. São Paulo: Paulus; Loyola, 2015. 
PULEO, A. H. Ecofeminismo: para otro mundo posible. Madrid: Ediciones Cátedra, 2011.

SALAZAR, M. R. Construyendo el poder desde el feminismo comunitario e desde la teología política feminista. Coisas do gênero, v. 2, n. 1, 2016. p. 53-64.

Renato Kirchner

Doutor em Filosofia pela UFRJ Universidade Federal do Rio de Janeiro Docente do Programa de Pós-Graduação em Ciências da Religião e da Faculdade de Filosofia da Pontifícia Universidade Católica de Campinas Campinas / SP-Brasil E-mail: renatokirchner00@gmail.com

Ceci Maria Costa Baptista Mariani

Doutora em Ciências da Religião pela Pontificia Universidade Católica de São Paulo Docente de Teologia do Departamento de Teologia da Pontifícia Universidade Católica de Campinas Campinas / SP-Brasil E-mail: cecibm@puc-campinas.edu.br

Luís Gabriel Provinciatto

Doutor em Ciências da Religião pela Universidade Federal de Juiz de Fora Doutor em Filosofia pela Universidade de Évora - Portugal Juiz de Fora / MG - Brasil E-mail: lgprovinciatto@hotmail.com

Recebido em: 29/10/2021

Aprovado em: 08/12/2021 